\title{
HIV-1 Antigens in Neurons of Cocaine-Abusing Patients
}

\author{
Milan Fiala ${ }^{*}, 1$, Elyse J. Singer ${ }^{2}$, Deborah Commins ${ }^{2}$, Tamara Mirzapoiazova ${ }^{3}$, Alexander Verin ${ }^{4}$, \\ Araceli Espinosa ${ }^{5}$, Kenneth Ugen ${ }^{6}$, Michael Bernas ${ }^{7}$, Marlys Witte ${ }^{7}$, Martin Weinand ${ }^{7}$ and \\ Albert S. Lossinsky,
}

\author{
${ }^{1}$ Departments of Medicine, UCLA School of Medicine, Los Angeles, California, USA \\ ${ }^{2}$ Department of Neurology, UCLA School of Medicine, Los Angeles, California, USA \\ ${ }^{3}$ University of Chicago, Department of Medicine, Section of Pulmonary and Critical Care Medicine, Chicago, Illinois, \\ USA \\ ${ }^{4}$ Medical College of Georgia, Vascular Biology Center, Augusta, Georgia, USA \\ ${ }^{5}$ Department of Neurobiology, UCLA School of Medicine, Los Angeles, CA, USA \\ ${ }^{6}$ Department of Molecular Medicine and Center for Molecular Delivery, University of South Florida College of \\ Medicine, Tampa, Florida, USA \\ ${ }^{7}$ Department of Surgery, University of Arizona, Tucson, Arizona, USA \\ ${ }^{8}$ Laboratory of Cell Culture, Neuroanatomy and Experimental Neuropathology, New Jersey Neuroscience Institute and \\ JFK Medical Center, Edison, New Jersey, USA \\ ${ }^{9}$ New York State Office of Mental Retardation, Department of Pathological Neurobiology, New York State Institute for \\ Basic Research in Developmental Disabilities, Staten Island, New York, USA
}

\begin{abstract}
Cocaine opens the blood-brain barrier by deregulating transcription of target genes. Here we show that cocaine at blood concentrations in drug abusers disrupts endothelial cell junctions in parallel with signaling by phosphorylation of extracellular signal-regulated kinase, myristoylated alanine-rich $\mathrm{C}$ kinase and myosin light chain. Cocaine effects may be important in vivo since the neurons of drug abusing patients with HIV-1 associated dementia displayed gp120, p24 and Nef.
\end{abstract}

Keywords: Blood-brain barrier, cocaine, intercellular junctions, Extracellular signal-regulated kinase, HIV-1, HIV-1associated dementia.

\section{INTRODUCTION}

Although the incidence of HIV-1-associated dementia (HAD) has been decreasing since the advent of HAART, the prevalence of chronic neurological disease associated with HIV-1 has been increasing. Drug abuse may be an important risk factor in chronic neurological complications of HIV-1 infection. There are compelling reasons why cocaine abuse might increase the risk of HIV-1 infection of the brain [1]. Cocaine opens the blood-brain barrier to HIV-1 [2] by remodeling brain microvascular endothelial cells (BMVEC's) and disrupting virus macropinocytosis and degradation in lysosomes [3].

We have shown that HIV-1 may use two different mechanisms to penetrate the blood-brain barrier (BBB): a "Trojanhorse" transport into the brain in monocytes and lymphocytes $[4,5]$ or macropinocytosis of cell-free virus in BMVEC's [6]. In this study, we examined the concentrations of cocaine

\footnotetext{
*Address correspondence to this author at the Orthopaedic Hospital Research Center, 615 Charles E. Young Drive South, Los Angeles, CA 90095735 8, USA; Tel: 310 206-6392; Fax: 310 825-5409;

E-mail: fiala@mednet.ucla.edu
}

necessary for cell signaling and disruption of BMVEC's in order to clarify the presence of HIV-1 antigens in neurons of drug abusing patients with HAD.

\section{METHODS}

\section{Brain Microvascular Endothelial Cells}

Human BMVEC's were isolated from temporal lobe tissues removed during neurosurgical procedures and cultured as previously described [6]. Confluent monolayers of BMVEC's were prepared by seeding 100,000 cells into each well of an 8- well tissue culture- treated slides (Becton Dickinson Falcon, Bedford, Massachusetts, USA) containing 0.5 $\mathrm{ml}$ of DME/F12 (InVitrogen, Carlsbad, California, USA) with $10 \%$ fetal calf serum and incubating cell cultures for 46 days to confluence. To study cocaine's signaling, cocaine (Research Triangle Institute, North Carolina, USA) (1:100 dilution of freshly diluted $100 x$ stock in DME/F12) was added to achieve the indicated concentration in the medium.

\section{Brain Tissues}

The National Neurological AIDS Bank at UCLA provided formalin-fixed, paraffin-embedded frontal lobe and hippocampal tissues of five HIV-1-positive patients (four 
patients had a history of drug abuse including cocaine with additional alcohol and opiate abuse in some; the last patient had no history of drug abuse) and two amyotrophic lateral sclerosis (ALS) brain tissues. The autopsy interval ranged between 5 to $6 \mathrm{~h}$ except that of one ALS patient, which was 22 h. The Manhattan HIV Brain Bank provided brain tissue of a patient with minor cognitive impairment who had brain lymphoma and was taking medically prescribed opiates. The UCLA Brain Bank provided HIV-1-negative control tissues (amyotrophic lateral sclerosis) and two brain tissues of HAD patients who died in the late 1980's. The protocol was reviewed and approved by the UCLA Institutional Review Board.

\section{Immunohistochemistry (IHC)}

Tissues were subjected to antigen retrieval solution (DAKO) in a steamer for $20 \mathrm{~min}$ and were treated with Dual endogenous enzyme block and Protein block (DAKO, Carpinteria, California, USA). IHC was performed by the Envision technique (with primary rabbit and mouse antibodies) or the LSAB 2 technique (with primary goat antibodies) (DAKO) as previously described [7]. The primary antibodies were anti-gp120, anti-p24, anti-Nef (all three, which are described below, were provided by the AIDS Research and Reference Reagent Program, NIH, Bethesda, USA), antiNeuN (Chemicon, Temecula, California, USA), anti-CD68 and anti-GFAP (DAKO).

Two gp120 monoclonal antibodies were used: ID6 [8] and 670-30D [9]. The murine ID6 monoclonal antibody was generated after immunization of a mouse with a recombinant gp160 immunogen. Subsequent analysis using screening of phage display libraries with ID6 indicated that the epitope was contained within amino acids 86-100 of the highly conserved $\mathrm{C} 1$ region of gp120. One of the phage mimotopes generated by screening with ID6 (designated phage 3.3) bound to ID6 with a high affinity. Two IHC studies were done using ID6 absorbed with the relevant gp120 epitope. In the first, equal volumes of the ID6 antibody $(1: 100)$ and recombinant gp120 JR-FL $(250 \mathrm{ng} / \mu \mathrm{L})$ were incubated at $37^{\circ} \mathrm{C}$ for $3 \mathrm{hrs}$ and, after ultracentrifugation, the top half of the suspension was used in IHC. Recombinant gp120 was produced in Chinese hamster ovary cells as described [10]. In the second study, ID6 antibody (1:100) was incubated with phage 2.13 (negative phage mimotope) or phage 3.3 (positive phage mimotope) [8] (each at 1:800) and processed as above.

Gag was detected using monoclonal anti-p25/24 (ISF2) and anti-p24 (AG 3.0); Nef was stained using anti-HIV-1 IIIB Nef (AE6) and anti-Nef (EH1).

\section{Transmission Electron Microscopy (TEM)}

BMVEC cultures grown on cover slips in 24-well plastic dishes were fixed by immersion according to standard protocols that take into consideration our desire to produce excellent ultrastructural preservation of EC cytoskeletal filaments, microtubules, and EC junctional complexes. For this reason, we fixed the BMVEC at room temperature (25EC) to avoid disruption of EC cytoskeletal components such as microtubules. The fixative contained $2.5-3.0 \%$ glutaraldehyde in 0.1 M sodium cacodylate buffer, $\mathrm{pH}$ 7.4 [11]. BMVEC were post-fixed with $1 \%$ osmium tetroxide, dehydrated in a graded series of ethanol, and en bloc stained with uranyl

acetate [12]. The coverslips were infiltrated with liquid epoxy plastic overnight in a desiccator at $25 \mathrm{EC}$. On the next day, in liquid plastic, the coverslips were sliced into several pieces and flat-embedded with the BMVEC positioned upward then polymerized in a $60 \mathrm{EC}$ oven overnight. For TEM and HVEM studies, plastic thick- and thin-sections were cut with either the Leica Ultracut UCT and Sorvall (MT-1) U1tramicrotomes and stained with lead and uranyl salts, according to standard protocols (Hayat, 1981). Thin-sections were collected on grids, stained with uranium and lead salts and examined with the FEI Morgagni Electron Microscope.

\section{Western Blot Analysis}

Confluent monolayers of BMVEC's were incubated overnight in serum-free DME/F12 medium and treated with cocaine as indicated. Cell extracts were prepared by washing cell monolayers three times with phosphate buffered saline (PBS), scraping the cells into SDS sample buffer $(125 \mathrm{mM}$ Tris $\mathrm{pH}$ $6.8,4 \%$ SDS, $10 \%$ glycerol, $0.006 \%$ bromophenol blue, $2 \% 2$ mercaptoethanol), then passing them through a 26-gauge needle. After $5 \mathrm{~min}$ of boiling, the protein samples were centrifuged for $2 \mathrm{~min}$ and separated by sodium dodecyl sulfate- $10 \%$ polyacrylamide gel electrophoresis (SDS-PAGE) [13]; the proteins were transferred to nitrocellulose membranes $(30 \mathrm{~V}$ for $18 \mathrm{~h}$ or $90 \mathrm{~V}$ for $2 \mathrm{~h}$ ) [14] and incubated with specific antibodies. The antibodies of interest included anti-phosphomyosin light chain 2 and anti-glyceraldehyde-3-phosphate dehydrogenase (GAPDH) (Cell Signaling, Danvers, Massachusetts, USA); anti-phospho-extracellular signal-regulated kinases 1 and 2 (Erk1/2) (New England BioLab, Beverly, Massachusetts, USA); anti-phosphor-specific myristoylated alanine-rich C kinase substrate (MARCKS) (ProteinTech Group, Chicago, Illinois, USA); and anti- myosin light chain (MLC) (Sigma, St. Louis, Missouri, USA). Immunoreactive proteins were detected with enhanced chemiluminescent detection system (ECL) according to the manufacturer's directions (Amersham, Little Chalfont, UK). The experiments were repeated three times. To evaluate the protein loading, the membranes were stained with GAPDH or MLC antibody.

\section{RESULTS}

\section{$10^{-5}$ to $10^{-7} M$ Cocaine Disrupt Confluent BMVEC's in Parallel with Cell Signaling}

Cocaine concentrations $10^{-5}$ to $10^{-7} \mathrm{M}$ disrupted endothelial junctions and produced gaps between BMVEC's (Fig. 1).

Cocaine concentrations $10^{-8} \mathrm{M}$ and below had minimal effects on BMVEC's. Benztropine is a therapeutic agent that, in addition to binding to the biogenic amine transporters and muscarinic receptors, binds with high affinity to a cocainebinding site on BMVEC's [3]. Similarly as cocaine, $10^{-5}$ to $10^{-7} \mathrm{M}$ benztropine produced gaps between endothelial cells (not shown). $10^{-5}$ to $10^{-7} \mathrm{M}$ cocaine treatment of BMVEC's induced phosphorylation of Erk 1/2, MARSKC and MLC (Fig. 2). Cocaine concentrations $10^{-8}$ and below did not consistently induce cell signaling. Benztropine has a higher affinity for the cocaine-binding site on BMVEC's than cocaine [3]. Accordingly, stimulation by $10^{-6} \mathrm{M}$ benztropine induced more prolonged signaling through Erk1/2 and MLC phosphorylation in comparison to cocaine (Fig. 2). 


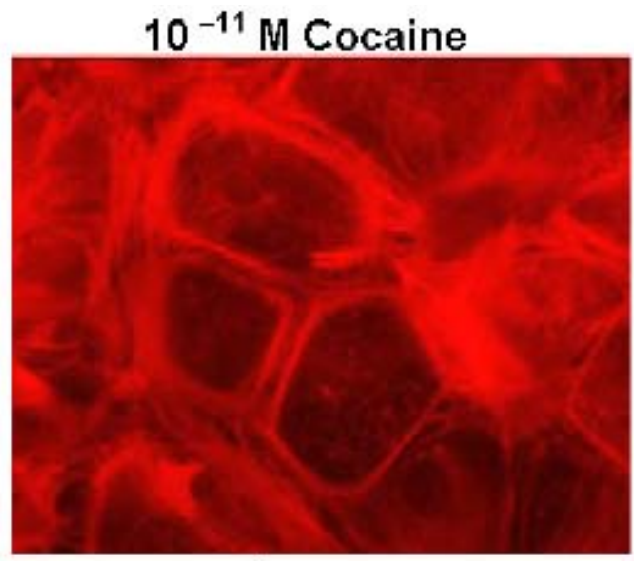

$10^{-9}$ M Cocaine

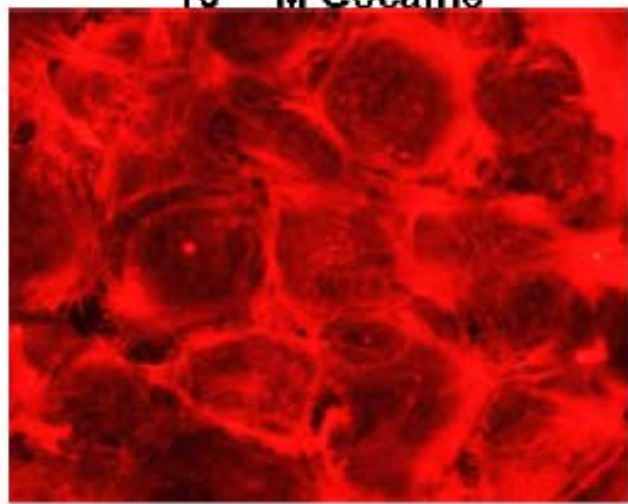

$10^{-7}$ M Cocaine

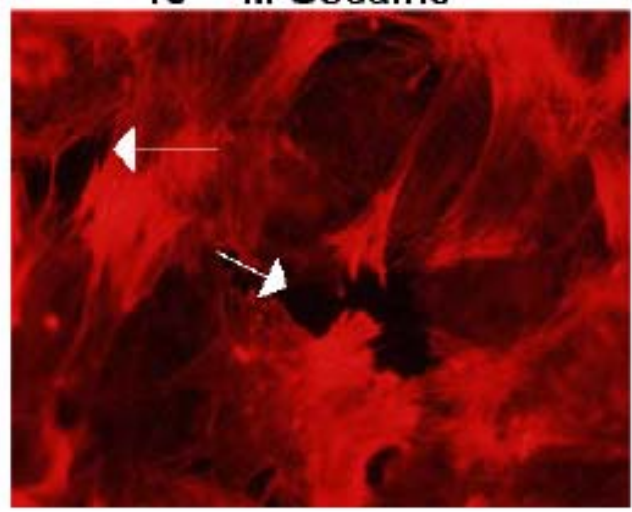

$10^{-5} \mathrm{M}$ Cocaine

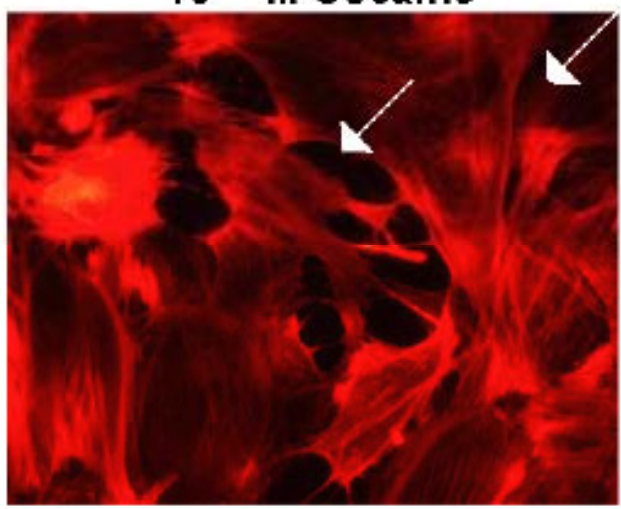

$10^{-10} \mathrm{M}$ Cocaine

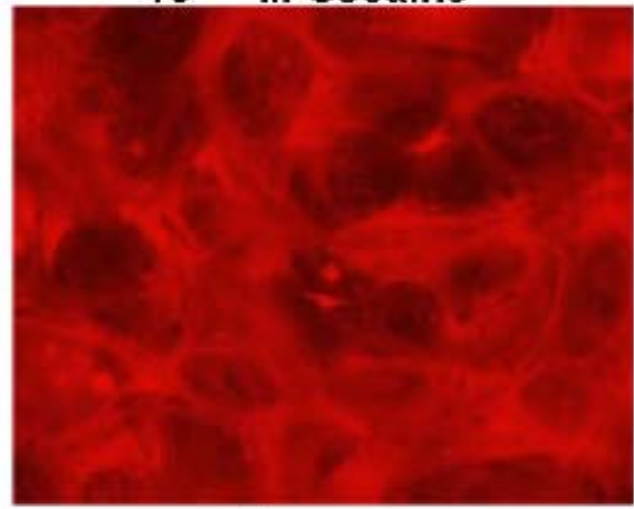

$10^{-8} \mathrm{M}$ Cocaine

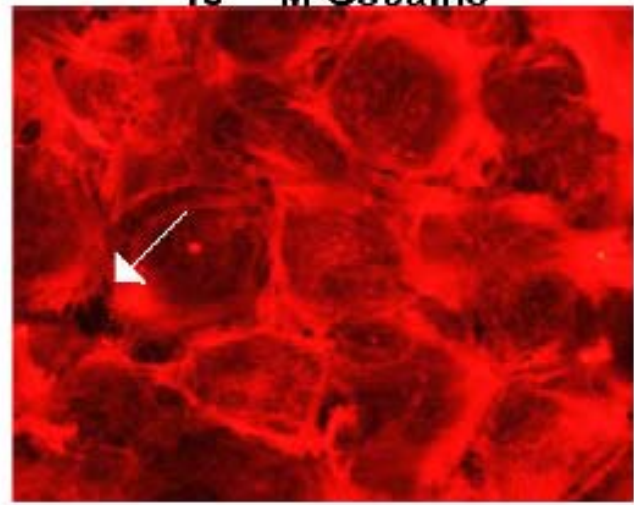

$10^{-6} M$ Cocaine

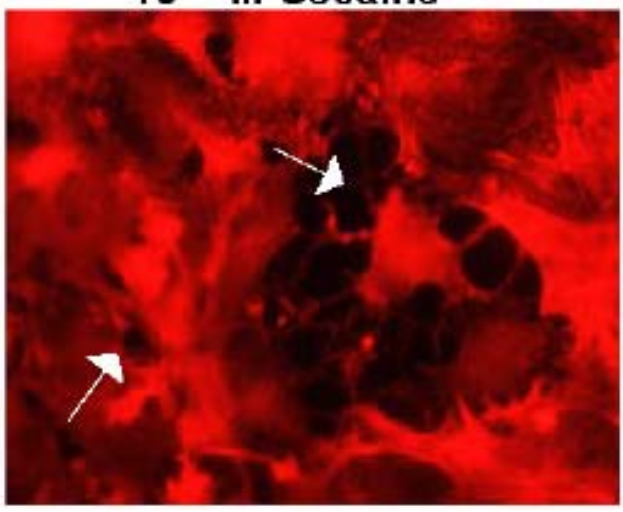

$10^{-4} M$ Cocaine

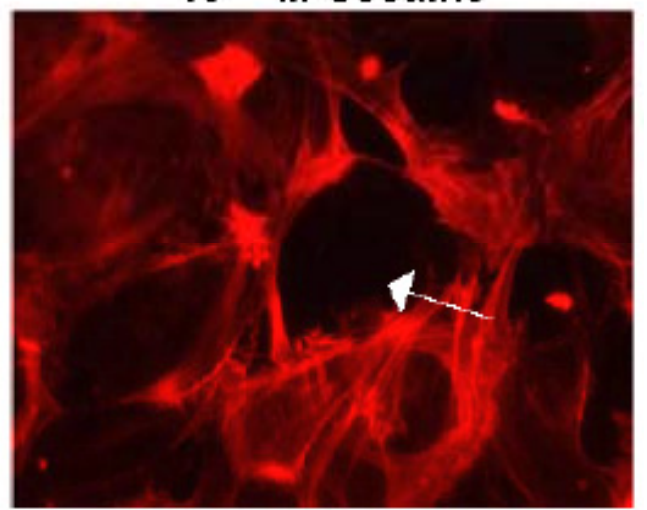

Fig. (1). Cocaine disrupts BMVEC junctions. Confluent BMVEC monolayers were treated with the indicated concentration of cocaine for $1 \mathrm{~h}$; the cells were then washed, fixed, stained with phalloidin-ALEXA 594 and photographed by Hamamatsu camera on the Olympus Bmax microscope (40x). The arrows indicate gaps between BMVEC's. 


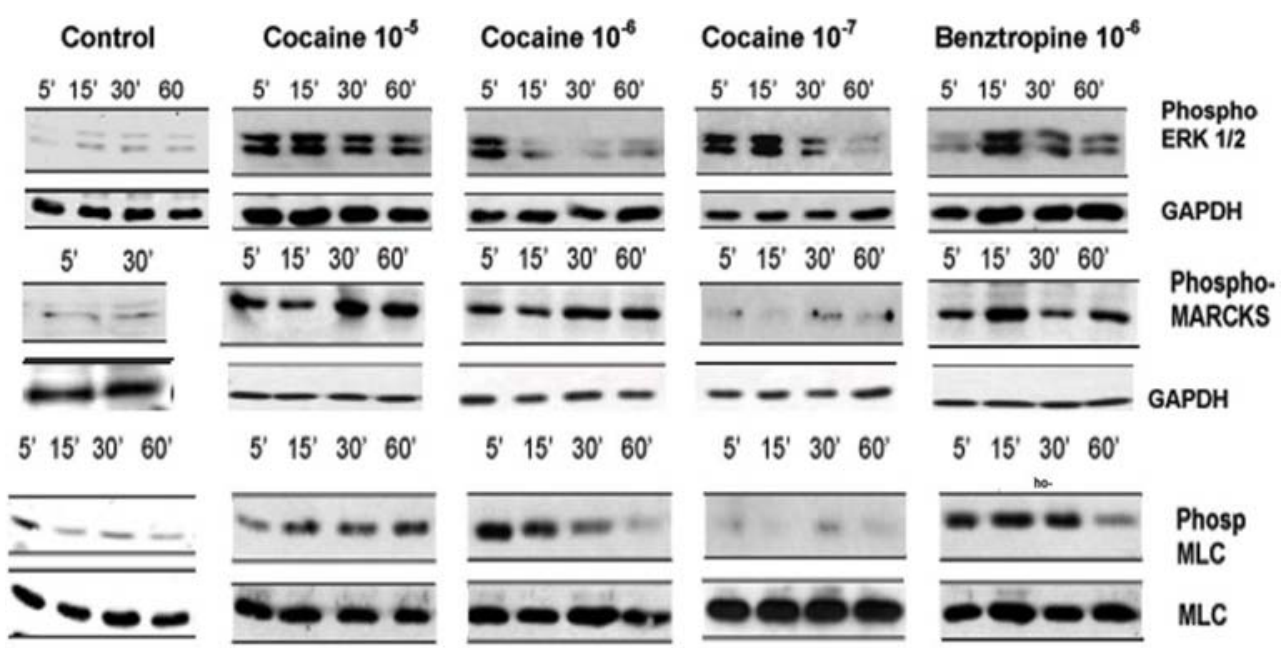

Fig. (2). Cocaine and benztropine induce phosphorylation of Erk 1/2, MARCKS and MLC in BMVEC's.

Confluent BMVEC monolayers were treated with the indicated concentration and time of exposure to cocaine; cell extracts were prepared and analyzed by SDS-PAGE with antibodies to phospho-Erk 1/2, MARCKS and MLC. Staining with antibodies to GAPDH and MLC demonstrated equal loading.

\section{Ultrastructural Features of Monocyte Migration Across BMVEC's}

In the $\mathrm{BBB}$ model, monocyte migration was stimulated by $\mathrm{MCP}-1$ in the lower chamber. Monocytes migrated between the endothelial cells, which became thick above each pore (Fig. 3A). Monocytes migrated through the pore into the brain chamber (Fig. 3B). The rate of monocyte migration was increased by cocaine, as previously published [2].

(A)

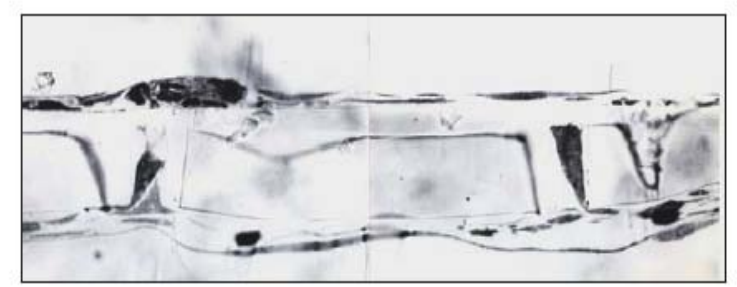

(B)

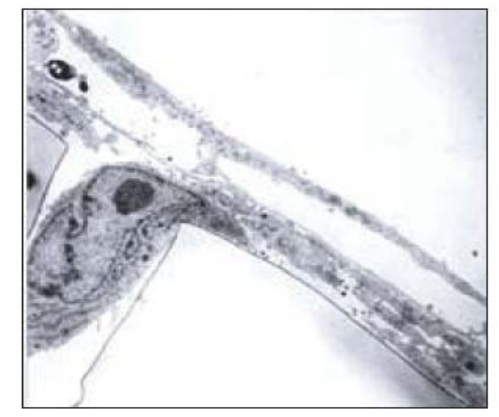

Fig. (3). Ultrastructural features of monocyte migration through the BMVEC model of the blood-brain barrier. (A) Endothelial layer becomes thick above the pores through which the monocytes are migrating $(1,000 x$ section of the BBB model with migrating monocytes). (B) Monocytes migrate between endothelial cells and through the pore (TEM, 10,000 x). 24-h treatment of BMVEC's with $10^{-6} \mathrm{M}$ cocaine produced robust vacuolization of the endothelial cell cytoplasm (Fig. 4) and increased monocyte transmigration, as previously published [15].

(a) Control

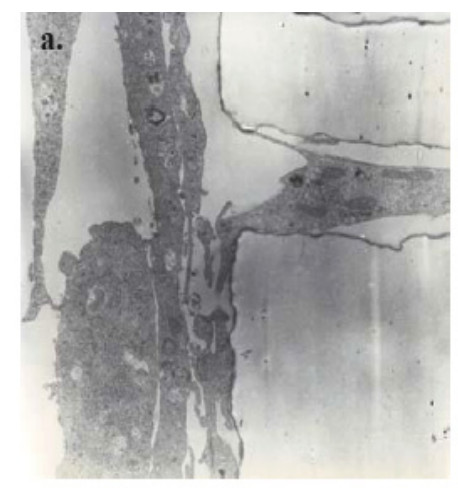

(b) Cocaine $10^{-6} \mathrm{M}$

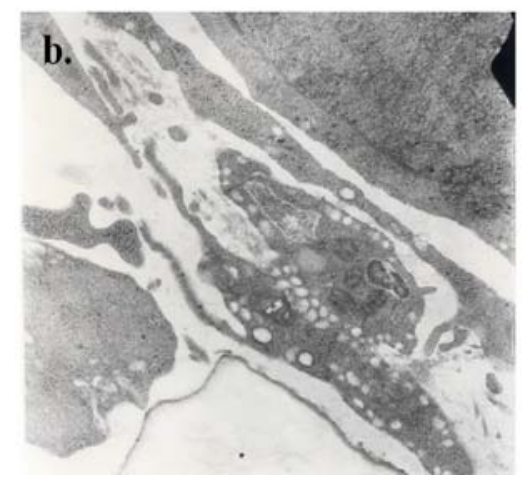

Fig. (4). Ultrastructural features of monocyte migration through the BMVEC model of the blood-brain barrier. Compared to the untreated cells (a), cocaine-treated BMVEC's (b) display cytoplasmic vacuolization (TEM, 10,000 x).

As shown above (Fig. 1), cocaine at the concentrations in the plasma of cocaine's addicts $\left(10^{-6} \mathrm{M}\right.$ to $\left.10^{-8} \mathrm{M}\right)$ disrupts BBB. We have searched for increased evidence of HIV-1 in brain tissues of drug-abusing patients with HAD. 
Frontal Lobe Neurons of Drug-Using Patients are Positive for gp120, p24 and Nef

To detect viral "foot-prints" in brain tissues, we performed IHC with the monoclonal gp120 antibody ID6 with brain tissues of six HAD patients, four with a history of drug abuse, one with a history of opiate use for medical reasons, and one without any history of drug use. All patients were intensively treated until their death with HAART. The neuropathology was remarkable for absence of perivascular infiltration by macrophages and lack of gp120 staining of microglia, which were noted in brain tissues of patients with HAD who died in the eighties (Fig. 5). The brain tissues of the patient without a history of drug abuse were completely negative for gp120 (Table 1).

However, the five patients with a history of drug abuse or medical use of morphine had expression of gp120 (brown) in neurons, as shown by double staining with MAP-2 antibody (red) (Fig. 6a), but not in astrocytes (Fig. 6b).

To confirm the specificity of gp120 staining with the ID6 antibody, this antibody was absorbed with the phage 3.3 mimotope (Fig. 6d), which removed the reactivity, whereas absorption with the unrelated phage 2.13 had no effect on the staining (Fig. 6c). Absorption of the ID6 antibody with gp120 also reduced neuronal staining (not shown).

Furthermore, ID6 antibody did not stain neurons of control patients (e.g., ALS case) and unrelated antibody (CD20) did not stain neurons in HAD brain tissues. In addition, neurons in the frontal lobe tissues were positively stained by two different p24 (Fig. 7a,b) and two different Nef antibodies (Fig. 7c,d). (a)

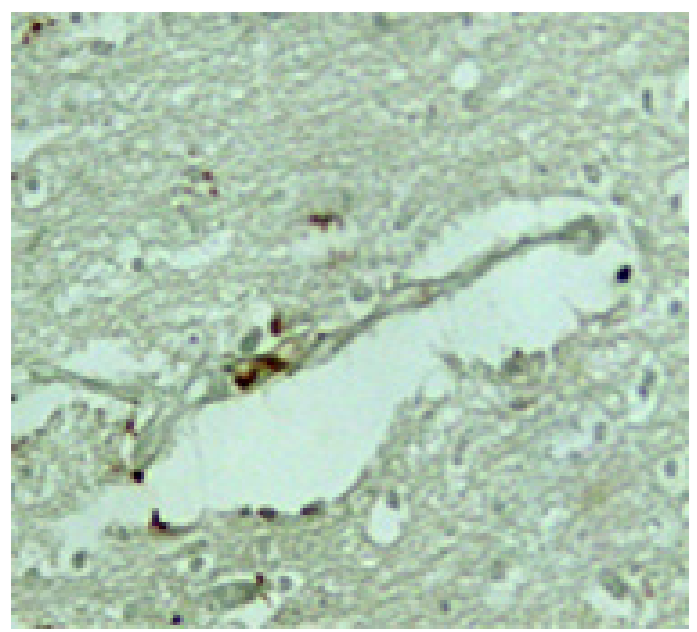

(b)

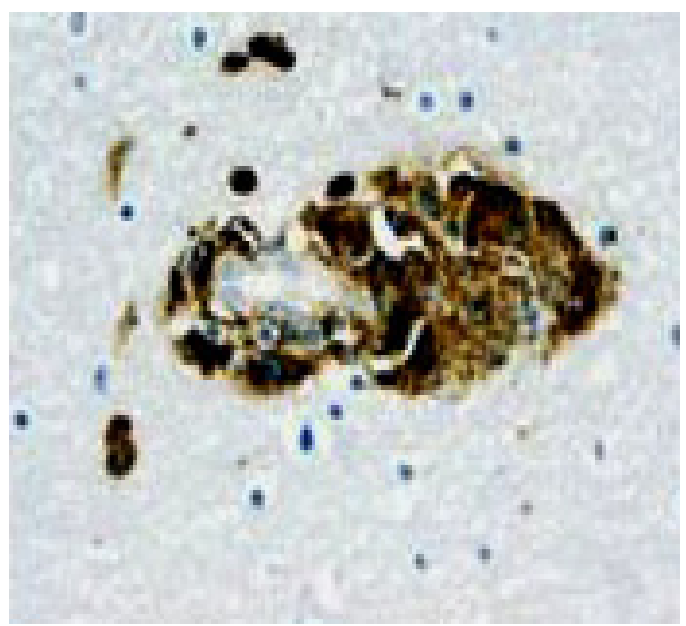

Fig. (5). Perivascular infiltration by macrophages in HAD brain tissues. (a) Minimal perivascular macrophage infiltration in patient 1 (IHC with CD68 antibody). (b) Robust macrophage infiltration of vessels in an AIDS patient dying in late 1980's.

Table.1. HIV-1 Positive ${ }^{\mathrm{a}}$ and Control $^{\mathrm{b}}$ Patients - Diagnostic $^{\mathrm{a}}$ and Virological ${ }^{\mathrm{b}}$ Data

\begin{tabular}{|c|c|c|c|c|c|c|c|}
\hline \multirow{2}{*}{ Subject } & \multirow{2}{*}{ Age/Sex } & \multirow{2}{*}{$\begin{array}{l}\text { Cocaine } \\
\text { Abuse }\end{array}$} & \multirow{2}{*}{$\begin{array}{c}\text { Other Risk } \\
\text { Factors }\end{array}$} & \multirow{2}{*}{ Neuropathological Diagnosis } & \multicolumn{3}{|c|}{ Neuronal Staining ${ }^{\mathrm{c}}$} \\
\hline & & & & & gp120 & p24 & Nef \\
\hline HIV 1 & $46 \mathrm{M}$ & No & Morphine $^{d}$ & White matter pallor, gliosis & + & + & N.D. \\
\hline HIV 2 & $29 \mathrm{~F}$ & Yes & No & Alzheimer type II gliosis & + & + & + \\
\hline HIV 3 & $58 \mathrm{~F}$ & Yes & No & N.D. & + & N.D & N.D. \\
\hline HIV 4 & $44 \mathrm{M}$ & Yes & Alcoholism & Alzheimer type II gliosis; HIV encephalitis & + & N.D. & N.D. \\
\hline HIV 5 & $34 \mathrm{~F}$ & Yes & No & HIV encephalitis; cryptococcal meningitis & + & + & + \\
\hline HIV 6 & $42 \mathrm{M}$ & No & No & Minimal non-diagnostic abnormalities & - & - & - \\
\hline Ctrl 1 & $69 \mathrm{M}$ & No & No & ALS; Anoxic-ischemic encephalopathy; laminar necrosis in occipital cortex & - & - & - \\
\hline $\mathrm{Ctrl} 2$ & $66 \mathrm{M}$ & No & No & ALS & - & N.D. & N.D. \\
\hline Ctrl 3 & $86 \mathrm{~F}$ & No & No & No neuropathology & - & N.D. & N.D. \\
\hline Ctrl 4 & $90 \mathrm{~F}$ & No & No & No neuropathology & - & N.D. & N.D. \\
\hline
\end{tabular}

aAll HIV subjects except \#6 had neurocognitive diagnosis of HAD.

bAll controls were HIV-1 negative. Control 1 and 2 had amyotrophic lateral sclerosis (ALS).

'Post-mortem frontal lobe and hippocampus.

${ }^{\mathrm{d}}$ Morphine for pain control. 

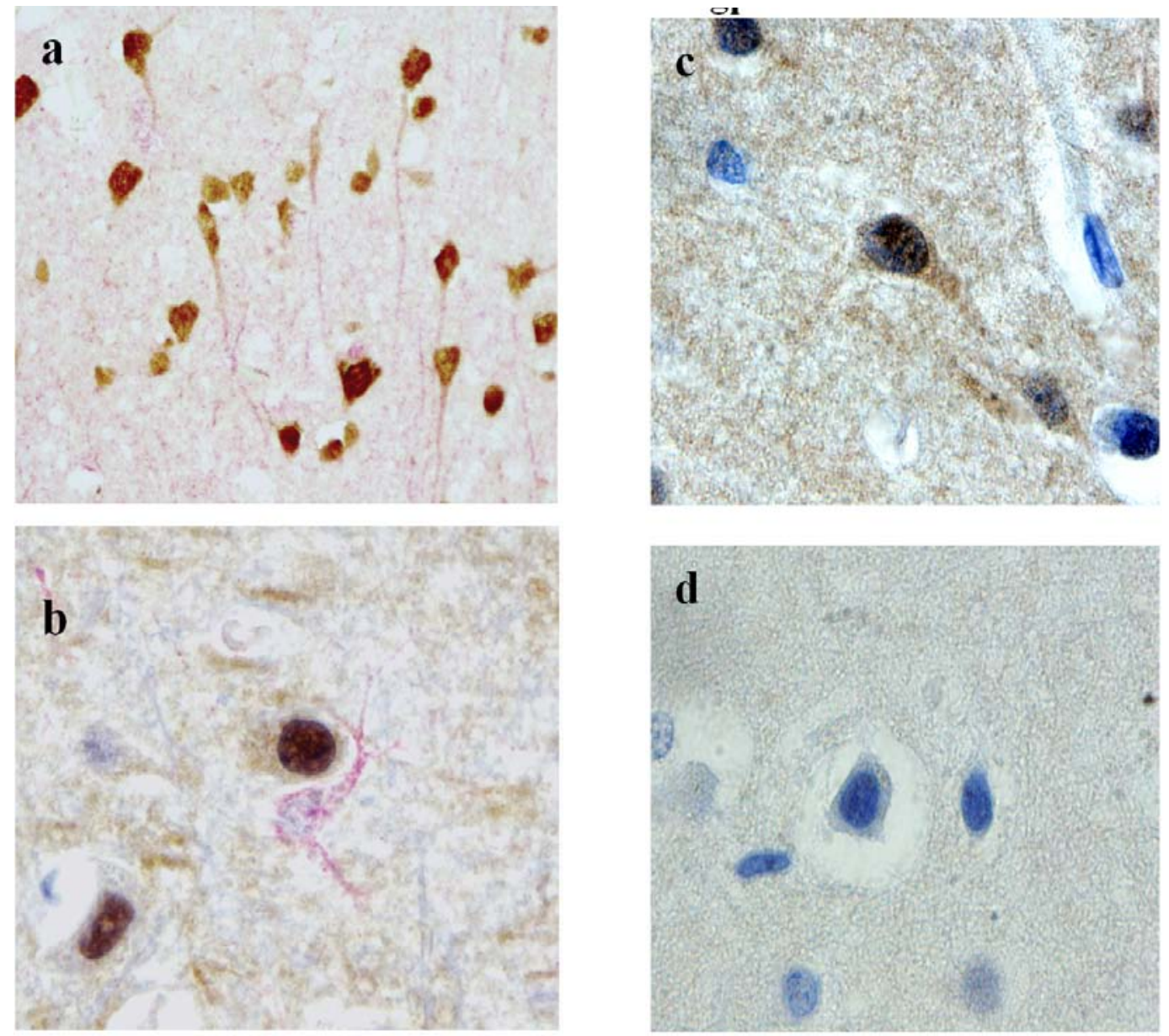

Fig. (6). (gp120). Immunohistochemical demonstration of HIV-1 antigens in frontal lobe neurons of the patient \#5 with HAD (the results of staining in patients \#1-4 were comparable). (a) Positive neuronal gp120 staining (anti-gp120 (ID6) (brown) and anti-MAP2 (red), 40x). (b) Positive gp120 staining of neurons and negative staining of astrocytes (anti-gp120 (ID6) (brown) and anti-GFAP (red), 40x). (c) Positive gp120 staining of neurons (anti-gp120 (ID6) absorbed with the negative phage 2.13, 100x). (d) Negative gp120 staining of neurons (antigp120 (ID6) absorbed with the positive phage 3.3, 100x).

\section{DISCUSSION}

We previously demonstrated that cocaine "opens" the BBB constructed with BMVEC's to HIV-1 entry [2]. In addition, cocaine induced transcriptional alterations in BMVEC's genes important for cell signaling, cytoskeleton organization, cell swelling, vesicular trafficking, and cell adhesion, which may lead to acute and long-term changes in the properties of the blood-brain barrier. Cocaine induced gaps between endothelial cells as early as $30 \mathrm{~min}$ after exposure [16]. However, since these effects involved $10^{-5}$ or $10^{-6}$ $\mathrm{M}$ concentrations, some doubt has persisted about the in vivo effects of cocaine abuse associated with plasma concentrations below $10^{-6} \mathrm{M}$. Here we show that cocaine concentrations as low as $10^{-7} \mathrm{M}$ induce cell signaling in parallel with disruption of cell junctions. Cocaine activates mitogen activated protein kinase (MAPK), protein kinase $\mathrm{C}$ (PKC), and MLC kinase pathways in BMVEC's as shown by an increase in ERK, MARCKS, and MLC phosphorylation, respectively. Paradoxically, the ERK response to cocaine appeared stronger at $10^{-7} \mathrm{M}$ compared to $10^{-6} \mathrm{M}$ cocaine. It has been known that cocaine dose response is not always linear. For example Carmaci et al. showed that cocaine might manipulate the cAMP PKA-Sig-1R and the cAMP-ERK-Sig-1R pathways in biphasic fashion [17]. MAPK and PKC path- ways are critically involved in an increase of endothelial paracellular permeability in different types of endothelium [18-20]. In addition, cocaine increased MLC phosphorylation, which initiates EC contraction and leads to gap formation and permeability increase $[18,21]$. The effects of cocaine appear to be pharmacological, since they are induced through a common binding site with benztropine [3].

HIV-1 neurotoxicity is attributed by one school to indirect mechanisms and by another school to direct virus presence in neurons. The indirect mechanisms, which have been more extensively investigated [22], are mediated by macrophage products, such as tumor necrosis factor- $\alpha$, plateletactivating factor, arachidonic acid and its metabolites, nitric oxide, quinolinic acid, and glutamate [23-25], and HIV-1 proteins, such as Tat and gp120, produced by macrophages and microglia [26-28]. Human studies of peripheral blood of HAD patients noted elevated cytokines and neurotoxins [22], and macrophage-specific proteins [29]. However, although some investigators still believe that neuronal toxicity is due solely to indirect mechanisms [30,31], neuronal expression of HIV-1 proteins, such as $\mathrm{Vpr}$ [32], and neuronal presence of HIV-1 DNA [33] have been described prior to our study and are made plausible by this study. 
(a)

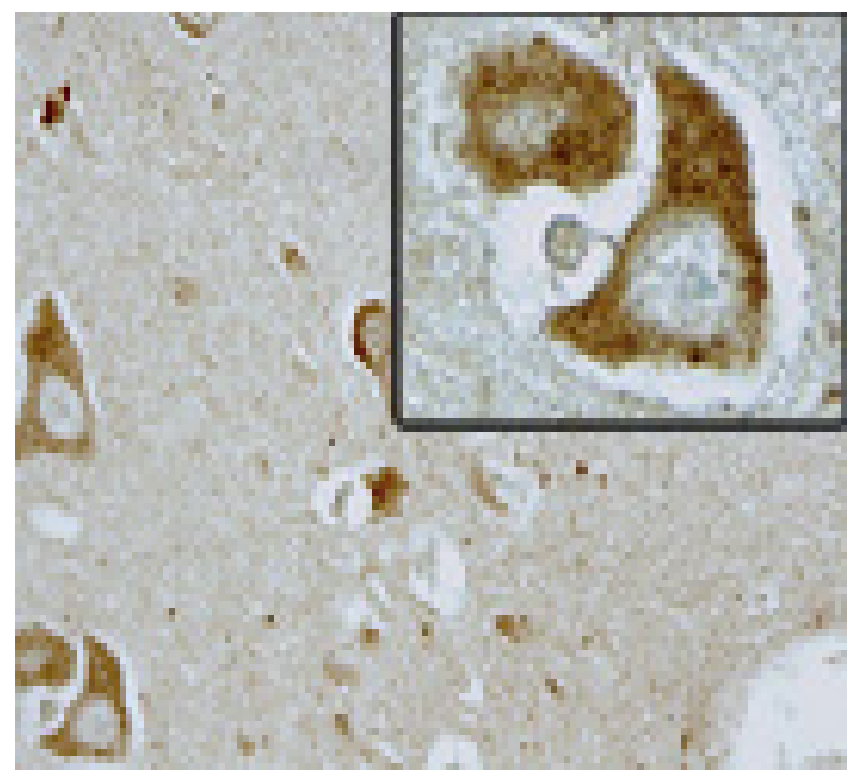

(c)

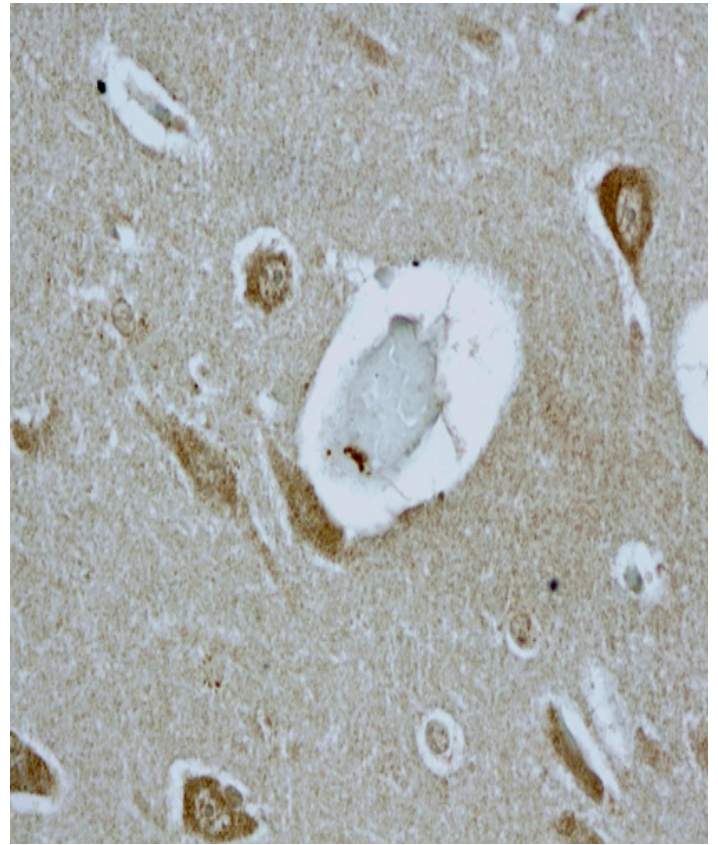

(b)

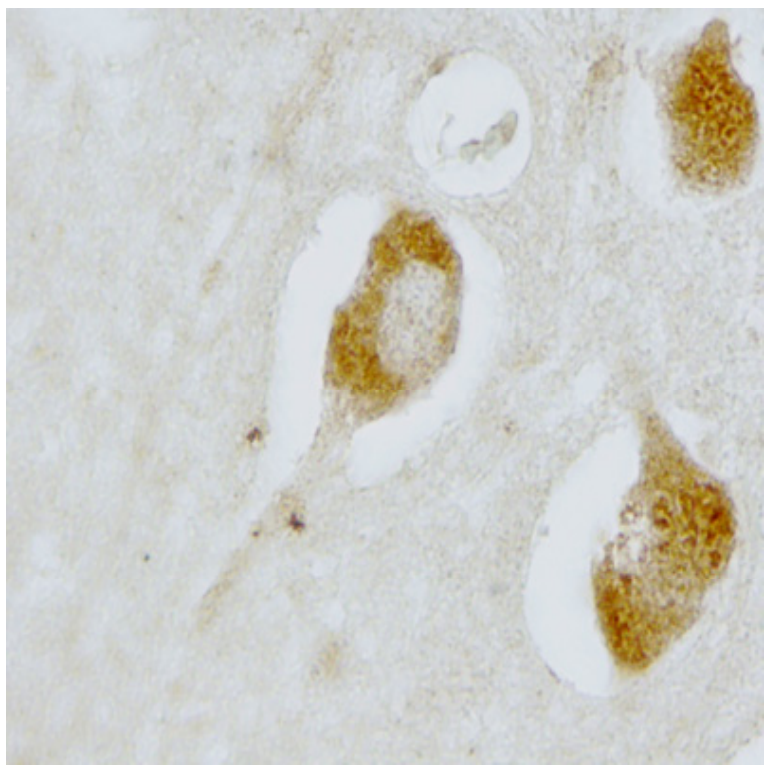

(d)

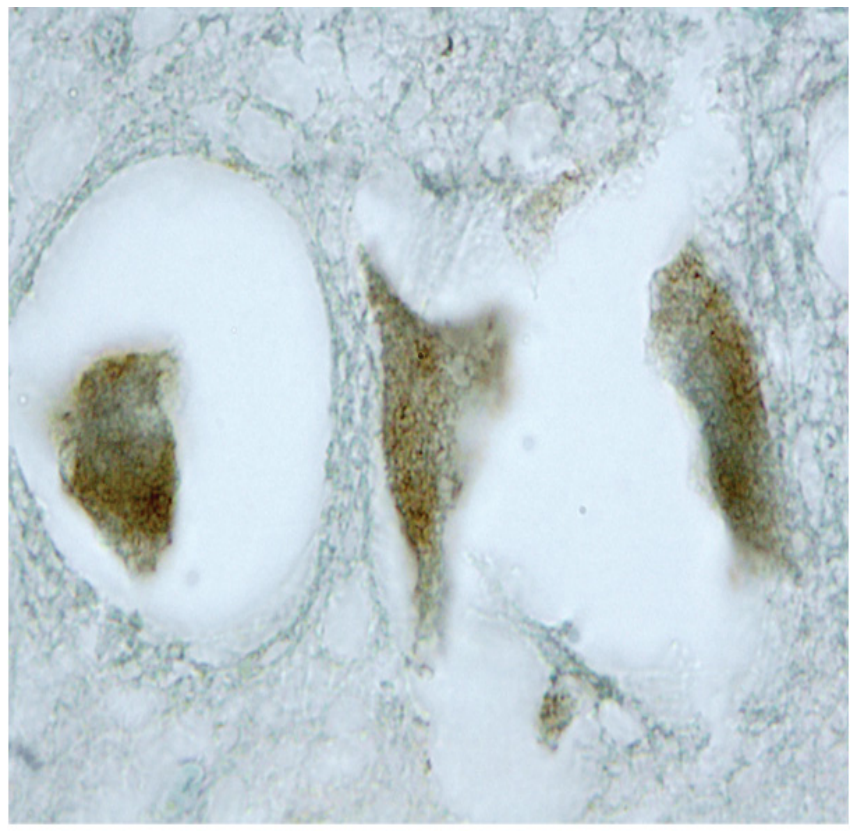

Fig. (7). (p24, Nef) Immunohistochemical demonstration of HIV-1 antigens in frontal lobe neurons of the patient \#5 with HAD (the results of staining in patients \#1-4 were comparable) (a). Positive neuronal staining with anti p24 (ISF2) (40x, inset 100x). (b) Positive neuronal staining with anti p24 (AG 3.0) (100x). (c) Positive neuronal staining with anti-Nef (AE6). (d) Positive neuronal staining with anti-Nef (EH1).

We have shown (a) absence of robust perivascular macrophage infiltration, and (b) presence of HIV-1 antigens, gp120, Nef and p24, in neurons of drug using HAD patients. Our patients received intensive HAART therapy, which curtailed high-grade HIV-1 viremia suffered by patients in 1980's and could have blocked immunological activation and brain migration of macrophages [4]. Interestingly, most patients with HAD seen at UCLA had a history of cocaine abuse, which could be due to the in vivo effects of cocaine showed in vitro by this study. The novel immunohistochemical observations of HIV-1 antigens in neurons of drug abusing HAD patients may be related to the robust effects of co- caine even at the plasma levels below $10^{-6} \mathrm{M}$, which may cause subtle breaks of BBB permitting penetration of viral proteins or infectious virus into the neuropil and, for unknown reason, selective invasion of neurons. In this regards, it is interesting that in a rat model gp120 is transported into cortical neurons by retrograde axonal transport from the striatum and hippocampus [34].

\section{ACKNOWLEDGEMENTS}

This project was supported by Grants HL63639 and HL63065 from the National Institutes of Health (to M.F.) 
and Grant NS 38841 (to E.S.). The AIDS Research and Reference Reagent Program, NIAID, NIH provided HIV reagents listed in Materials and Methods. The Manhattan HIV Brain Bank and the National Neurological AIDS Bank at UCLA of the National Neurological AIDS Consortium provided autopsy brain tissues of patients with HAD. We are indebted to Karen Manoutcharian and Goar Gevorkian, Nacional Autonoma de Mexico, for mimotope phages; Jonathan Said, UCLA Department of Pathology, for confirming our results with the ID6 antibody; Erin Foley for assistance with cell signaling studies in BMVEC's; Elizabeth Tran, Erika Artinger, and Rana Hojatmehr for immunohistochemical studies; and Michelle Mahanian, Schehrezade Khan, and Jane Lee for assistance with preparation of the manuscript.

\section{REFERENCES}

[1] Nath A, Maragos WF, Avison MJ, Schmitt FA, Berger JR. Acceleration of HIV dementia with methamphetamine and cocaine. J Neurovirol 2001; 7(1): 66-71.

[2] Zhang L, Looney D, Taub D, et al. Cocaine opens the blood-brain barrier to HIV-1 invasion. J Neurovirol 1998; 4: 619-26.

[3] Fiala M, Eshleman AJ, Cashman J, et al. Cocaine increases human immunodeficiency virus type 1 neuroinvasion through remodeling brain microvascular endothelial cells. J Neurovirol 2005; 11: 1-11.

[4] Persidsky Y, Stins M, Way D, et al. A model for monocyte migration through the blood-brain barrier during HIV-1 encephalitis. J Immunol 1997; 158(7): 3499-510.

[5] Liu Y, Tang XP, McArthur JC, Scott J, Gartner S. Analysis of human immunodeficiency virus type $1 \mathrm{gp} 160$ sequences from a patient with HIV dementia: evidence for monocyte trafficking into brain. J Neurovirol 2000; 6 Suppl 1: S70-81.

[6] Liu NQ, Lossinsky AS, Popik W, et al. Human immunodeficiency virus type 1 enters brain microvascular endothelia by macropinocytosis dependent on lipid rafts and the mitogen-activated protein kinase signaling pathway. J Virol 2002; 76(13): 6689-700.

[7] Fiala M, Liu QN, Sayre J, et al. Cyclooxygenase-2-positive macrophages infiltrate the Alzheimer's disease brain and damage the blood-brain barrier. Eur J Clin Invest 2002; 32(5): 360-71.

[8] Gomez-Roman VR, Cao C, Bai Y, et al. Phage-displayed mimotopes recognizing a biologically active anti-HIV-1 gp120 murine monoclonal antibody. J Acquir Immune Defic Syndr 2002; 31(2): 147-53.

[9] Zolla-Pazner S, O'Leary J, Burda S, et al. Serotyping of primary human immunodeficiency virus type 1 isolates from diverse geographic locations by flow cytometry. J Virol 1995; 69(6): 3807-15.

[10] Mossman SP, Bex F, Berglund P, et al. Protection against lethal simian immunodeficiency virus SIVsmmPBj14 disease by a recombinant Semliki Forest virus gp160 vaccine and by a gp120 subunit vaccine. J Virol 1996; 70(3): 1953-60.

[11] Haudenschild CC, Cotran RS, Gimbrone MA Jr, Folkman J. Fine structure of vascular endothelium in culture. J Ultrastruct Res 1975; 50(1): 22-32.

[12] Hayat MA. The production of artifacts. Ultrastruct Pathol 1981 Jan-Mar;2(1):93; discussion

[13] Laemmli UK. Cleavage of structural proteins during the assembly of the head of bacteriophage T4. Nature 1970; 227(5259): 680-5.

[14] Towbin H, Staehelin T, Gordon J. Electrophoretic transfer of proteins from polyacrylamide gels to nitrocellulose sheets: procedure and some applications 1979. Biotechnology 1992; 24: 145-9.

[15] Gan X, Zhang L, Taub D, et al. Cocaine enhances endothelial adhesion molecules and leukocyte migration. Clin Immunol 1999; 91: $68-76$.
[16] Fiala M, Lin J, Ringman J, et al. Ineffective phagocytosis of amyloid-beta by macrophages of Alzheimer's disease patients. J Alzheimers Dis 2005; 7(3): 221-32; discussion 55-62.

[17] Cormaci G, Mori T, Hayashi T, Su TP. Protein kinase A activation down-regulates, whereas extracellular signal-regulated kinase activation up-regulates sigma-1 receptors in B-104 cells: Implication for neuroplasticity. J Pharmacol Exp Ther 2007; 320(1): 202-10.

[18] Bogatcheva NV, Garcia JG, Verin AD. Molecular mechanisms of thrombin-induced endothelial cell permeability. Biochemistry (Mosc) 2002; 67(1): 75-84.

[19] Verin AD, Liu F, Bogatcheva N, et al. Role of ras-dependent ERK activation in phorbol ester-induced endothelial cell barrier dysfunction [In Process Citation]. Am J Physiol Lung Cell Mol Physiol 2000; 279(2): L360-70.

[20] Bogatcheva NV, Dudek SM, Garcia JG, Verin AD. Mitogenactivated protein kinases in endothelial pathophysiology. J Investig Med 2003; 51(6): 341-52.

[21] Dudek SM, Garcia JG. Cytoskeletal regulation of pulmonary vascular permeability. J Appl Physiol 2001; 91(4): 1487-500.

[22] Persidsky Y, Gendelman HE. Mononuclear phagocyte immunity and the neuropathogenesis of HIV-1 infection. J Leukoc Biol 2003; 74(5): 691-701.

[23] Genis P, Jett M, Bernton EW, et al. Cytokines and arachidonic metabolites produced during human immunodeficiency virus (HIV)-infected macrophage-astroglia interactions: implications for the neuropathogenesis of HIV disease. J Exp Med 1992; 176(6): 1703-18.

[24] Wesselingh SL, Power C, Glass JD, et al. Intracerebral cytokine messenger RNA expression in acquired immunodeficiency syndrome dementia. Ann Neurol 1993; 33(6): 576-82.

[25] Williams MA, Turchan J, Lu Y, Nath A, Drachman DB. Protection of human cerebral neurons from neurodegenerative insults by gene delivery of soluble tumor necrosis factor p75 receptor. Exp Brain Res 2005; 165(3): 383-91.

[26] Nath A, Haughey NJ, Jones M, Anderson C, Bell JE, Geiger JD. Synergistic neurotoxicity by human immunodeficiency virus proteins Tat and gp120: protection by memantine. Ann Neurol 2000; 47(2): 186-94.

[27] van de Bovenkamp M, Nottet HS, Pereira CF. Interactions of human immunodeficiency virus-1 proteins with neurons: possible role in the development of human immunodeficiency virus-1-associated dementia. Eur J Clin Invest 2002; 32(8): 619-27.

[28] Mattson MP, Haughey NJ, Nath A. Cell death in HIV dementia. Cell Death Differ 2005; 12 Suppl 1: 893-904.

[29] Wojna V, Carlson KA, Luo X, et al. Proteomic fingerprinting of human immunodeficiency virus type 1-associated dementia from patient monocyte-derived macrophages: A case study. J Neurovirol 2004; 10(Suppl 1): 74-81.

[30] Bissel SJ, Wiley CA. Human immunodeficiency virus infection of the brain: pitfalls in evaluating infected/affected cell populations. Brain Pathol 2004; 14(1): 97-108.

[31] Mocchetti I, Bachis A, Masliah E. Chemokine receptors and neurotrophic factors: Potential therapy against aids dementia? J Neurosci Res 2008; 86(2): 243-55.

[32] Wheeler ED, Achim CL, Ayyavoo V. Immunodetection of human immunodeficiency virus type 1 (HIV-1) Vpr in brain tissue of HIV1 encephalitic patients. J Neurovirol 2006; 12(3): 200-10.

[33] Trillo-Pazos G, Diamanturos A, Rislove L, et al. Detection of HIV1 DNA in microglia/macrophages, astrocytes and neurons isolated from brain tissue with HIV-1 encephalitis by laser capture microdissection. Brain Pathol 2003; 13(2): 144-54.

[34] Bachis A, Aden SA, Nosheny RL, Andrews PM, Mocchetti I. Axonal transport of human immunodeficiency virus type 1 envelope protein glycoprotein 120 is found in association with neuronal apoptosis. J Neurosci 2006; 26(25): 6771-80. 